\title{
Leprakolonien på Spinalonga
}

Spedalskhet er en sykdom med lang historie, der menneskelige tragedier og medisinske fremskritt følges ad. Norsk pionerinnsats har en klar plass i historien. Selv om lidelsene fra denne sykdommen har mange ansikter og groteske historier, er det få steder interneringen av spedalske var satt i slikt omfattende system som på den greske øya Spinalonga.

\section{Arne Johan Norheim}

arne.johan.norheim@hlkbb.no

Nasjonalt forskningssenter innen komplementær og alternativ medisin Universitetet i Troms $\varnothing$ og

Vitalisklinikken, Harstad

\section{Tove Karin Norheim}

Vitalisklinikken, Harstad

Spinalonga (gresk $\Sigma \pi \imath v \alpha \lambda{ }^{\gamma} \gamma \kappa \alpha$ ) er en liten ø, like øst for Kreta. Man kommer dit med båt, vanligvis fra tettstedet Elounda ca. 1,5 km unna, eller landsbyen Plaka som er nærmeste skysstasjon, bare 250 meter fra øya.

Vi besøkte øya våren 2012. Med bakgrunn i et beskjedent kildegrunnlag, hovedsakelig to nyere bøker $(1,2)$, ønsker vi å dele våre inntrykk med Tidsskriftets lesere.

\section{Leprabasillen}

I leprahistorien har Norge hatt viktige bidrag. Det norske lepraregisteret ble opprettet i 1856 som verdens første nasjonale pasientregister (3), og Gerhard Henrik Armauer Hansen (1841-1912) sto for en internasjonal pionerbedrift da han oppdaget leprabasillen i 1873 (4).

Selv om det er 140 år siden Hansen beskrev leprabasillen, er spedalskhet fortsatt et betydelig medisinsk problem på verdensbasis med om lag 250000 nye tilfeller årlig, majoriteten av disse i India. Om lag en tredel av nye pasienter har nerveskader og omfattende funksjonshemninger ved diagnosetidspunktet (5). Sosial stigmatisering i kombinasjon med manglende kunnskap om leprasykdom hos pasienten gjør at mange som rammes, unnviker å oppsøke behandling i de tidlige stadier av sykdommen (6).
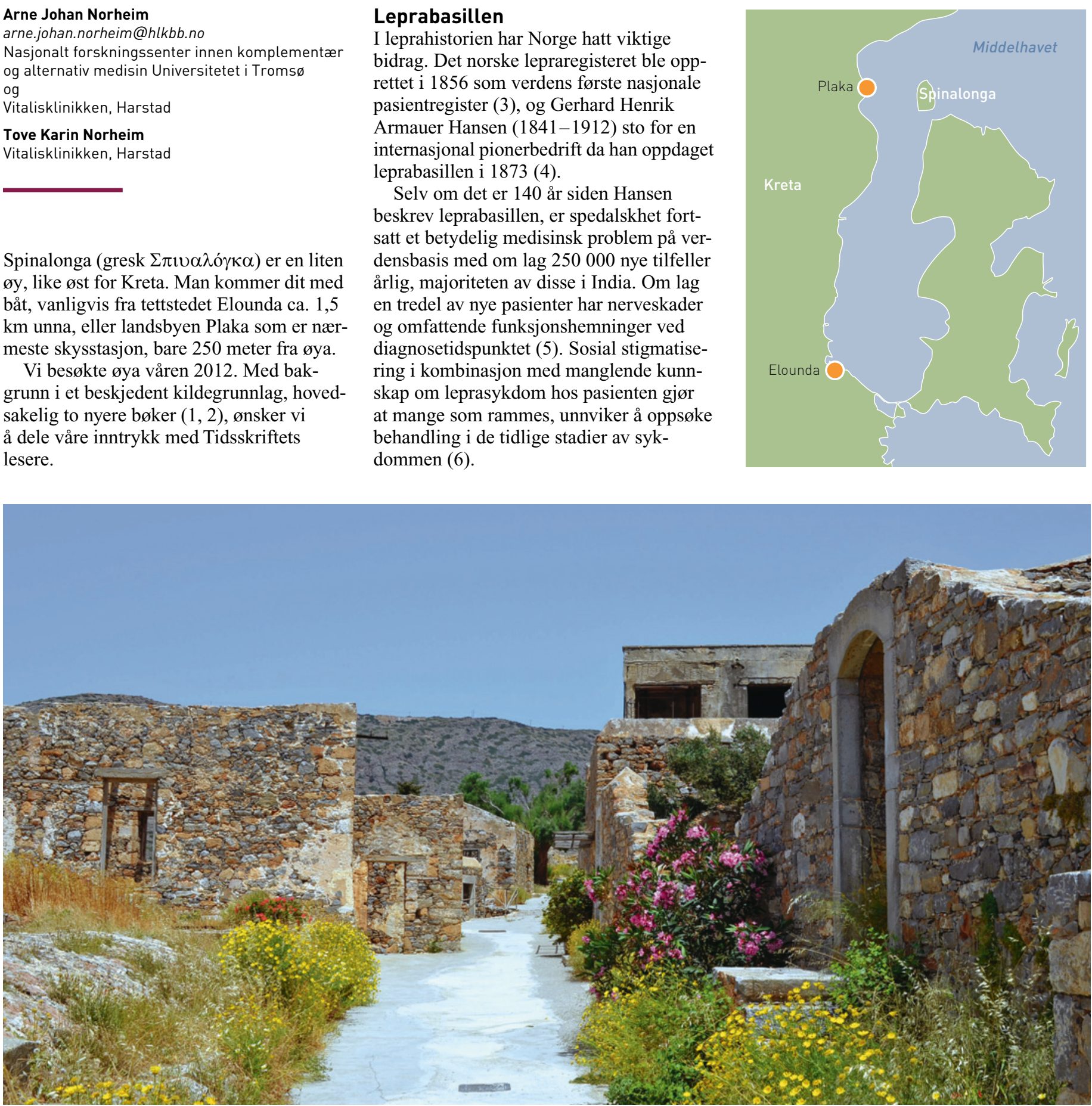

I disse husene bodde mange pasienter. I enden av hovedgaten skimtes til høyre toppen av to sovesaler med til sammen 48 rom som ble bygd for pleie av syke spedalske som hadde behov for hospitalisering. Alle foto privat 


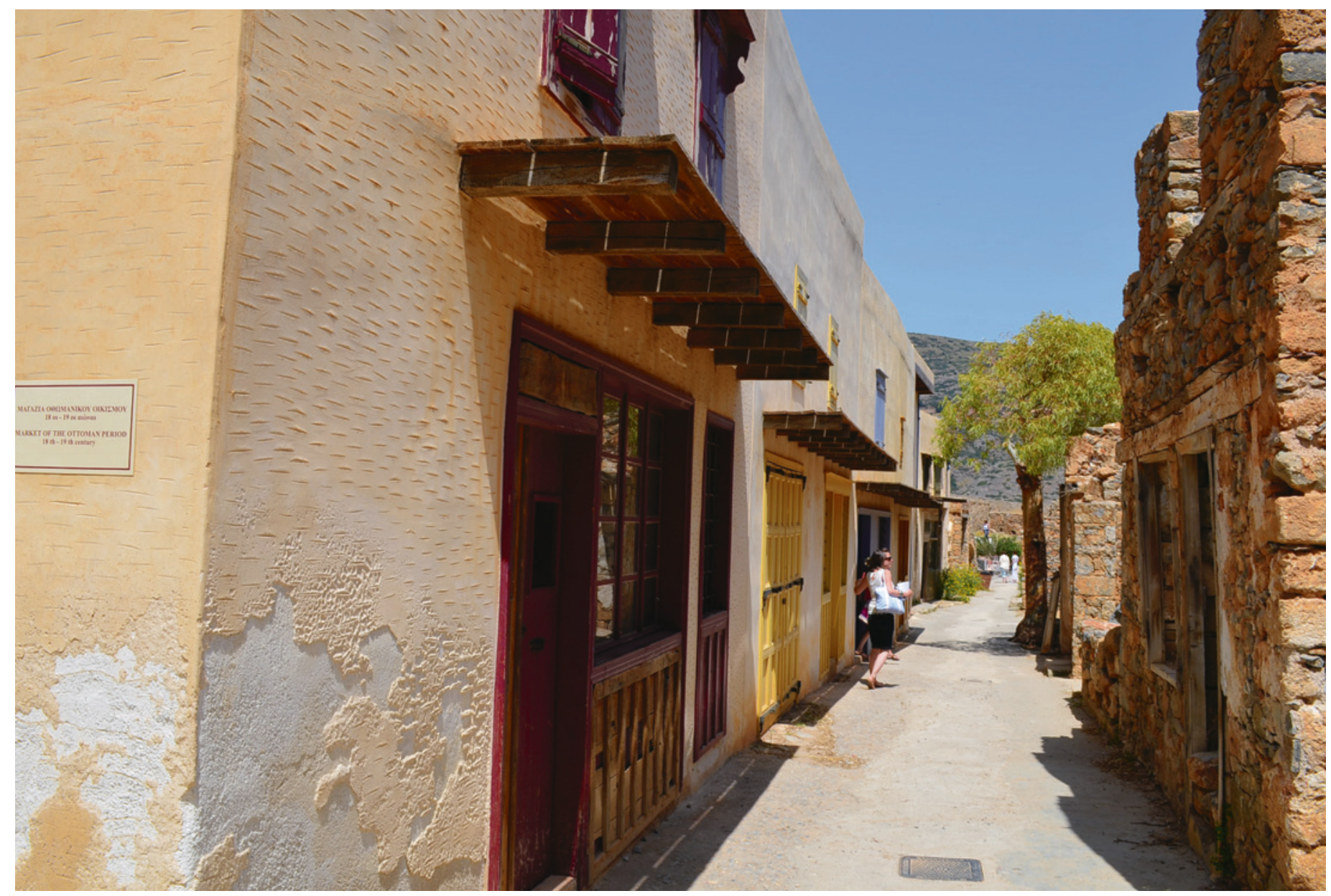

Hjertet i Spinalonga-samfunnet var den om lag 200 meter lange hovedgaten. Der ble det spilt klassisk musikk i høyttalere ut mot gaten, og de spedalske kunne sitte på kafé, nyte sin raki og ta et slag backgammon

\section{Spinalonga}

Da venetianerne på 1200-tallet okkuperte Hellas, ble Spinalonga raskt utpekt som strategisk viktig for å forsvare sjøveien mot Øst-Middelhavet. På 1500-tallet bygde de et stort festningsverk, og enkelte deler fortsatt kan ses. Under den tyrkiske okkupasjon fra 1700-tallet flyktet flere muslimer hit pga. den religiøse konflikten på Kreta, og på det meste hadde øya over 1100 innbyggere $(1,7)$.

På den tiden var Spinalonga et velstående handelssentrum. Krigshandlingene mellom grekere og tyrkiske muslimer på slutten av 1800-tallet endte imidlertid med sprenging og store ødeleggelser av det veldrevne samfunnet. Da den greske stat ble deklarert i 1898, var det kanskje ikke tilfeldig at Spinalonga i 1903 ble utpekt som leprakoloni for å gjøre hevd på øya og for å drive ut all tidligere bosetting (1).
Spinalonga ble pga. frykt for smitte aldri okkupert under den annen verdenskrig. Øysamfunnet var faktisk en del av motstandsbevegelsen ved å videresende nyheter fra London og Kairo og utstede og dele ut løpesedler på øya og i befolkningen for ørig (1).

\section{Leprakoloniens første periode}

De første spedalske ankom Spinalonga i 1904, og i løpet av det neste tiåret ble et betydelig antall forflyttet, ikke bare fra Kreta, men også fra resten av landet, og faktisk også fra utlandet. I starten var det de sykeste som ble isolert på øya. Spedalske pasienter med betydelige deformiteter ble overlatt i festningsruinene uten noe velorganisert helsestell (1).

Det er vanskelig å forestille seg lidelsene og prøvelsene disse pasientene ble stilt overfor, både med tanke på praktisk livber- ging og den totale isolasjonen fra familien. Det finnes svært lite litteratur fra leprakoloniens første par tiår, men Spinalonga omtales i denne perioden som «the island of the living dead» (1). Gjennom oppslag på øya og lokal informasjon tegnes det for oss et dystert bilde av leprakoloniens første tidsperiode.

Trolig var det opp mot 1000 pasienter som ble internert på Spinalonga i perioden 1904-57. Antallet er usikkert, ikke bare pga. dårlig kontroll med overføringen, men et betydelig antall tok også livet sitt ved å drukne seg eller ved å hoppe i steingrunnen utenfor festningsmurene. Innledningsvis var det full isolasjon på Spinalonga, og på øya vaiet et gult flagg som varslet om smittsom sykdom. Det var til å begynne med heller ikke lov å nærme seg øya, og fiske måtte skje i en avstand på minst 200 meter (1). 


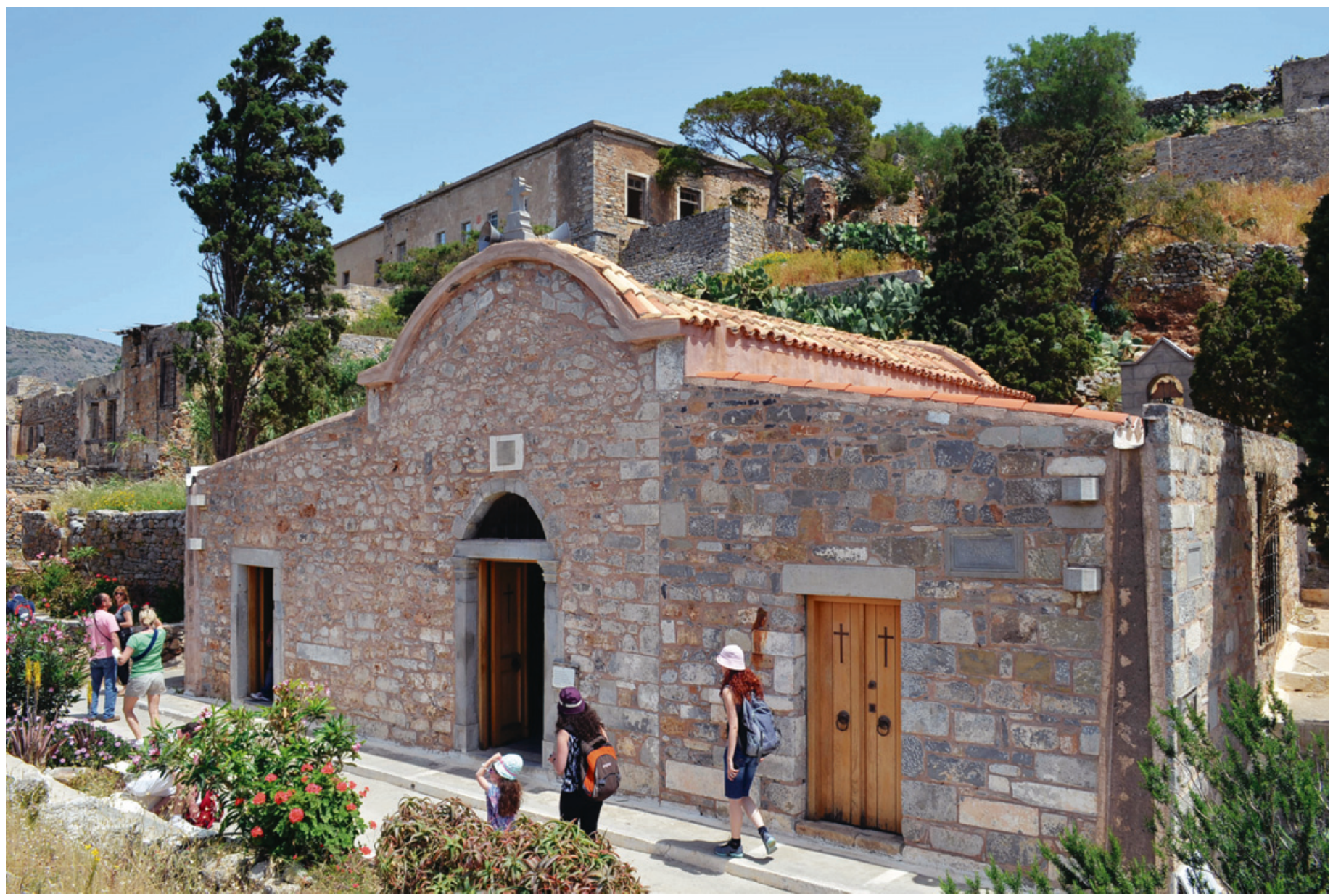

I forgrunnen ses den over 300 år gamle kirken, Agios Panteleimon, som sist var renovert i 1953 for penger samlet inn blant de spedalske på øya. Kirken var sete for alle slags religiøse seremonier og tallrike timer i ettertenksom bønn for leprasyke. I bakgrunnen ses sykehuset der nye pasienter og akutt syke ble tatt hånd om

\section{Leprakoloniens siste periode}

Fra 1930-årene ble forholdene betydelig bedre. Mye av æren tillegges en ung jurist, Epaminodas Remoundakis, som etter at han kom som pasient til Spinalonga, begynte å organisere samfunnet. Med donasjoner fra noen velstående grekere ble det bl.a. bygd en generator på øya, og det før elektrisitet var vanlig på landområdene omkring. De hygieniske forholdene bedret seg også betraktelig, det ble etablert både vaskeri og desinfeksjonsrom (1).

Pasientene begynte å praktisere sine yrker, og det ble etablert bl.a. frisør og kafe. I hovedgaten ble det hengt opp høyttalere som formidlet klassisk musikk, og øya fikk egen kino. Hovedgaten etterlater oss en forestilling av en smal gate i en alminnelig gresk, liten landsby. På skolen som ble etablert, ble det sågar gitt ut en egen avis. I ettertid har en av de eldste i Spinalongasamfunnet sagt at «fra nå av var ikke Spinalonga lenger et helvete, bare en fangelandsby med menneskets gode og dårlige sider og egenskaper» (1).

Til tross for den håpløse situasjonen må tro og håp ha stått sentralt for pasientene, for på den lille øya var det ikke mindre enn tre gudshus. Kanskje dels fordi spedalskhet fra gammelt av var betegnet som et tegn på religiøs urenslighet? Den største kirken ligger sentralt i hovedgaten, like nedenfor sykehuset. Presten var en del av sykehusstaben, og en svært viktig institusjon i leprakolonien for sørgende, søkende syke (1). Kirken er en viktig informant for besøkende med sine skrifter og bøker.

Det praktfulle sentrale kirkebygget understreker inntrykket av at kirken var sentral for pasientene som levde sine liv på Spinalonga.

\section{Medisinsk arbeid på Spinalonga}

Den første legen kom til øya rundt 1910 for å gjøre frivillig, ulønnet arbeid blant de spedalske. Hovedoppgaven var å gi medisinsk behandling samt å journalføre pasientens sykdomsutvikling. I tillegg var det en viktig oppgave å utarbeide årsrapport til myndighetene om tilstanden i kolonien (1).

Fra 1930-årene ble sykehuset, to tilhørende pasientboliger med 24 rom i hver, etablert. Fra denne tiden av ble utstyr og datidens medikamenter tilgjengelig, og sykehuset fikk en vesentlig rolle i øysamfunnet. Gjennom de siste årene besto staben ved sykehuset av en lege som sammen med en regnskapsfører administrerte hele øysamfunnet. I tillegg var det en person som arbeidet med desinfeksjon av boliger og gjenstander, fem sykepleiere, åtte båtpersonell, ti kvinner som vasket klær, ti kvinner som pleide de spedalske, og en prest (1).

I 1948 kom det internasjonale gjennombruddet $\mathrm{i}$ behandlingen av lepra, og Spinalonga var tidlig med på utprøving av nye antimikrobielle medikamenter, i hovedsak dapson. I Aten fikk et nytt behandlingssenter ansvar for behandlingen av spedalske, og i de lokale samfunnene ble det også vektlagt sosial rehabilitering av de som var vellykket medikamentelt behandlet (2).

\section{Livet på Spinalonga}

Det må ha vært en stor overgang for pasientene å komme til Spinalonga - der de ble ledet gjennom den enorme festningsporten. Over porten sto det inngravert en fri oversettelse av Dantes Inferno om inngangen til helvete. Inskripsjonen ønsket velkommen til et sted i sorg og smerte, og oppfordret til å legge alt håp bak seg. De nyankomne ble heller ikke ønsket velkommen av øyas beboere, istedenfor «velkommen» sa man bare «kom» (2).

Spinalonga var nok de første årene langt på vei en oppbevaringsanstalt. Etter hvert ble det imidlertid et velorganisert samfunn der mange spedalske faktisk levde et godt liv. Kontakten med slektninger på fastlandet ble gjenopptatt, og det var etter hvert tillatt for friske pårørende å gå i land på Spina- 


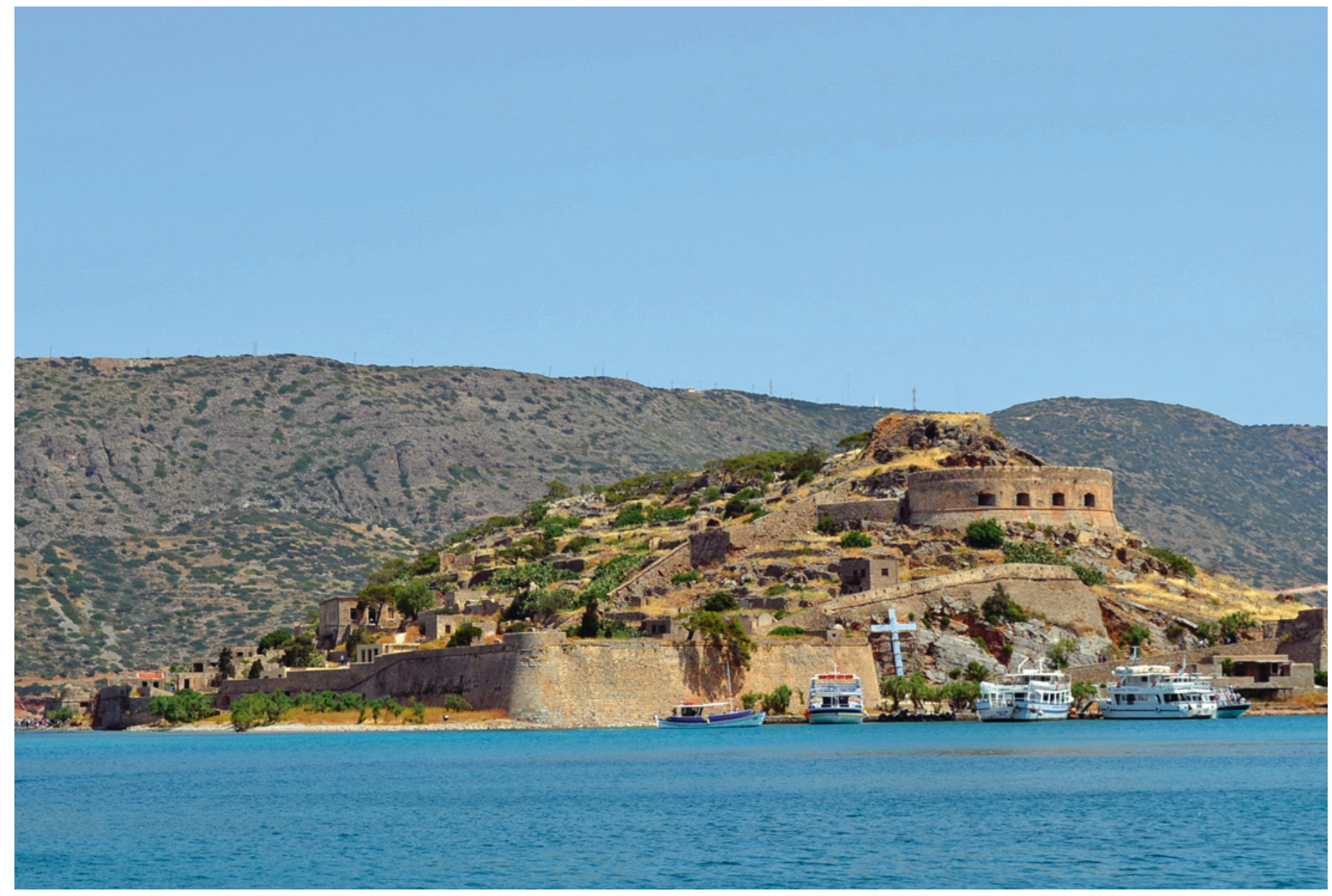

Spinalonga er den lille øya med et stort festningsverk. Bak disse murene holdt man bortimot 1000 spedalske internert i perioden fra 1903 til 1957

longa, men det fantes regler om hvordan de skulle forholde seg der. Ingen omfavnelser, og de skulle ikke spise ved samme bord (1).

Presten på øya hadde frie fullmakter til å oppheve tidligere ekteskap på fastlandet, og for dem som fant kjærligheten på Spinalonga, å velsigne nye samliv. Det ble også født bortimot 40 barn på øya, men så snart de var undersøkt av lege og funnet friske fra lepra, ble de tatt fra foreldrene og plassert i fosterhjem eller hos slektninger på fastlandet (2).

Noen kremmere blant de syke klarte å så slå seg opp med kafédrift, små utsalg og noen la seg faktisk opp en liten formue. Den greske stat ga 50 drakmer til hver pasient og dessuten fikk pasientene penger fra familie og venner.

Opptjent formue ble så sendt tilbake til fastlandet, men som for brev og andre forsendelser, først etter omfattende desinfeksjon og rengjøring (1).

Victoria Hislops debutroman Øya, som kom på norsk i 2007, omhandler livet på Spinalonga og ble en internasjonal bestselger. Gjennom romanfiguren Alexis fortelles en historie i kjærlighet og tårer om de utslag leprasykdommen hadde i det forrige århundre (8).

\section{Inntrykk fra Spinalonga}

I dag er øya en stor turistattraksjon, som årlig tiltrekker seg 30000 besøkende. I tillegg til boka Øya har en gresk TV-serie om livet på Spinalonga nok bidratt betydelig til oppsving $\mathrm{i}$ interessen for det forgangne spedalsksamfunnet.

Med medisinsk kunnskap om spedalskhet evner man til dels å forestille seg hvordan livet på Spinalonga må ha vært. Lidelsene sitter på en måte fast $i$ veggene, både på sykehuset,i sovesalene, kirken og festningsruinene. Og som helsepersonell kjente vi flere ganger en slags stolthet over at «Hansen's disease» ofte brukes om lepra i skrifter, turistbøker og fortellinger om den spedalske sykdom på Spinalonga.

\section{Arne Johan Norheim (f. 1961)}

er dr.philos., spesialist i allmennmedisin og seniorforsker.

Forfatter har fylt ut ICMJE-skjemaet og oppgir ingen interessekonflikter.

\section{Tove Karin Norheim (f. 1958)}

er sykepleier.

Forfatter har fylt ut ICMJE-skjemaet og oppgir ingen interessekonflikter.
Litteratur

1. Antonis A. Spinalonga - the island of the living dead. Heraklion, Hellas: Typokreta forlag, 2011.

2. Mammakis G. The oly metropolis of Petra and Cherronisos. Spinalonga: the island of suffering, faith and hope. Heraklion, Hellas: Typokreta forlag, 2011

3. Irgens LM, Bjerkedal T. Epidemiology of leprosy in Norway: the history of The National Leprosy Registry of Norway from 1856 until today. Int J Epidemiol 1973; 2: 81-9.

4. Irgens LM. Oppdagelsen av leprabasillen. Tidsskr Nor Lægeforen 2002; 122: 708-9.

5. Rodrigues LC, Lockwood DN. Leprosy now: epidemiology, progress, challenges, and research gaps. Lancet Infect Dis 2011; 11: 464-70.

6. Irgens LM, Nedrebø Y. Sandmo S et al. Å tallfeste lidelse. Førde: Selja Forlag, 2006.

7. Wikipedia. Spinalonga. http://no.wikipedia.org/ wiki/Spinalonga (4.6. 2012).

8. Hislop V. Øya. Oslo: Schibsted, 2007.

Mottatt 21.5. 2012, første revisjon innsendt 17.7. 2012, godkjent 4.10. 2012. Medisinsk redaktør Siri Lunde. 